\title{
Dynamics of infant mortality changes in Podkarpackie province in the years 2000-2017, forecast for the future. Retrospective study
}

\author{
Grażyna Hejda', Paulina Hejda', Monika Binkowska-Bury', Artur Mazur² \\ 'Institute of Nursing and Health Sciences, Faculty of Medicine, University of Rzeszow, Rzeszow, Poland \\ ${ }^{2}$ Department of Paediatrics, Paediatric Endocrinology, and Diabetes, Faculty of Medicine, University of Rzeszow, Rzeszow, Poland
}

\section{ABSTRACT}

Introduction: Mortality among children is a major problem for many countries and international organisations. Although mortality among children under five years old is declining around the world (including infant mortality), in many countries this progress is still worryingly slow.

Aim of the study: To determine dynamics of infant mortality changes in the Podkarpackie province in the years 2000-2017 and study the trend for the future.

Material and methods: The material for the study was information on infant deaths registered in the years 2000-2017 in Poland and the Podkarpackie province, taking into account the child's sex and place of residence. The data was obtained from the Central Statistical Office. The total mortality rate of infants and newborns per 1000 live births and the average annual rate of decline in the infant mortality rate were calculated. In mortality forecasts for the subsequent years 2018-2025, a curvilinear regression model was applied using the exponential function.

Results: In the years 2000-2017 in Podkarpackie province, infant mortality, like neonatal mortality, decreased by more than a half (from 7.17 deaths per 1000 live births in infants in 2000 and 5.13 deaths per 1000 live births in newborns to 3.28 and 2.42, respectively, per 1000 live births in 2017). The average annual rate of decline in infant mortality in Poland amounted to $4.1 \%$, while in Podkarpackie province it was $4.5 \%$. In the group of newborns, the rate was slightly lower and amounted to $3.9 \%$ and $4.3 \%$, respectively. In Poland, the excess mortality of boys between 20 and 25\% was found, while in Podkarpackie large fluctuations were observed (from $4 \%$ to $43 \%$ in particular years). The number of infant deaths both in the city and in the countryside decreased by $45-60 \%$, in the Podkarpackie province and in Poland. The forecast value of infant mortality in Podkarpackie province for 2018-2025 is between 3.80 (2018) and 2.85 (2025) per 100 live births.

Conclusions: In the years 2000-2017 in Podkarpackie province, infant mortality as well as neonatal mortality decreased by more than a half (from 7.17 deaths per 1000 live births for infants and 5.13 per 1000 live births for newborns in 2000 to 3.28 and 2.42, respectively, in 2017). The phenomenon of excess mortality of boys was found among infants. The infant mortality rate in rural areas in Podkarpackie province remained at a similar level to the national rate, while in the city in 2004-2006 it clearly exceeded it. The predicted infant mortality up to 2025 will show a downward trend.

\section{KEY WORDS:}

infant mortality, sex differentiation, place of residence, trend analysis.

\section{ADDRESS FOR CORRESPONDENCE:}

Grażyna Hejda, Institute of Nursing and Health Sciences, Faculty of Medicine, University of Rzeszów, 16A Rejtana St., 35-310 Rzeszow, Poland, ORCID: 0000-0002-7157-762X, e-mail: ghej@wp.pl 


\section{INTRODUCTION}

In Poland, a continuous trend of decreasing infant mortality is observed. In 2017, the infant mortality rate determining the number of infant deaths per 1000 live births was 3.99 and was lower by over 4 points than at the beginning of the analysed period and lower by over 15 points compared to $1990.70 \%$ of infant deaths occurred before the end of the first month [1]. In 2017, approx. 5.4 million children under the age of five years died in the world, including 4.1 million infants. In the first 28 days, about 2.5 million newborns died, one million of whom on the first day after birth. Many of them could be saved by simple and inexpensive means and the medical treatments that modern civilisation can provide. Mortality among children continues to be a major problem for a large number of countries and international organisations. Although the mortality rate of children under five years of age (including infant mortality) is decreasing worldwide, the progress is still slow in at least 50 countries around the world. With current trends regarding mortality reduction for children under five years of age, 56 million children will die in 2018-2030 and half of them will be newborns [2]. In 2010, during the UN Summit on the Millennium Development Goals, a strategy was adopted for Women, Children, and Youths for 2016-2030. It obliges Member States to reduce the mortality of children under five years old to 25 deaths per 1000 live births, and neonates to 12 deaths per 1000 live births. This strategy emphasises the right of women, children, and young people to physical and mental health, which allows full participation in shaping prosperous and sustainable societies [3]. "The level of infant mortality reflects the socio-economic and health situation of a given society and the level of civilisation development" - as Jołkiewicz claims, which also indicates the importance of social determinants of pregnancy and their impact on the biological condition of newborns [4].

The aim of the paper was to determine the dynamics of infant mortality changes in Podkarpackie province in the years 2000-2017 and to present the trend for the future.

It is worth mentioning that Podkarpackie province is the southernmost province of Poland, situated on the border with Ukraine and Slovakia. It is an agro-industrial region. According to data from the Central Statistical Office, as of June 30,2018 , the area was inhabited by $2,128,747$ people, of whom 1,252,941 reside in rural areas and 875,806 in towns. It should be emphasised that Podkarpackie province is also one of the ecologically cleanest environments in Poland, with extensive areas of natural terrain (about $45 \%$ of the area is occupied by legally protected areas) constituting a genuine oasis of nature in Europe.

\section{MATERIAL AND METHODS}

The material for the study was information on infant deaths recorded in the years 2000-2017 in Podkarpackie province and in the whole of Poland. The data was obtained from the Central Statistical Office. An analysis of neonatal mortality rate was performed (number of deaths from 0 to 27 days of life per 1000 live births) and total mortality rate of infants (number of infant deaths in the first year of life per 1000 live births) in Poland and in Podkarpackie province, taking into account the child's sex and place of residence. The mean annual rate of decline in infant mortality in 2000-2017 in Poland and in Podkarpackie province was calculated with division into newborns, other infants, place of residence, and sex. In the mortality forecasts for Podkarpackie province for subsequent years (2018-2025), a curvilinear regression model was used with the exponential function, because in the analysed case, it was characterised by the best adjustment to empirical data.

\section{RESULTS}

In the analysed period, the number of deaths of newborns and infants decreased both in Podkarpackie province and in Poland. In 2000 in Podkarpackie, there were 169 deaths of infants, while in 2017 this number decreased to 72 . At the same time, the number of infant deaths in Poland decreased from 3067 to 1604 (Table 1).

The number of infant deaths decreased by more than half in Podkarpackie province (57\%) and by almost half in Poland (48\%) similarly to the death rate of newborns. The observed decreasing trend of deaths occurred both among newborns and other infants (Table 1).

Similar features in the analysed period also characterised the infant mortality rate per 1000 live births. It decreased in the case of Podkarpacie province from 7.17 in 2000 to 3.28 in 2017 (i.e. by 54\%), while in the case of Poland - from 8.11 in 2000 to 3.99 in 2017 (i.e. by $51 \%$ ) (Fig. 1). The infant mortality rate decreased similarly reaching 2.42 in 2017 for Podkarpacie (2000 - 5.13, a 53\% decrease), and 2.83 for Poland (2000 - 5.59, a 49\% decrease). The infant mortality rate for the province was higher than the national rate in the years 2003-2007, 2010-2012, and 2014-2016, while in the remaining years the relationship between them was the opposite (Table 2).

In the whole analysed period, both in Podkarpackie province and in the whole country, the phenomenon of excess mortality of boys among infants was observed, i.e. the number of deaths of boys exceeded the number of deaths of girls. In the case of Poland, this relation was maintained at all times within the limits of 20-25\%, while in Podkarpackie province large fluctuations were observed (from $4 \%$ in 2000 to $43 \%$ in 2006) (Table 3).

When assessing the infant mortality rate per 1000 live births in 2000-2017 by sex, the increased period (compared to the country) of boys' mortality in Podkarpacie province was observed in 2004-2006, 2010-2012, and 2014-2016, and thus included the period when infant mortality in the region predominated over the national 
TABLE 1. Infant mortality trend in the years 2000-2017

\begin{tabular}{|c|c|c|c|c|c|c|}
\hline \multirow[t]{3}{*}{ Years } & \multicolumn{6}{|c|}{ Number of deaths } \\
\hline & \multicolumn{3}{|c|}{ Podkarpackie province } & \multicolumn{3}{|c|}{ Polish } \\
\hline & Total & Neonates & Other infants & Total & Neonates & Other infants \\
\hline 2000 & 169 & 121 & 48 & 3067 & 2116 & 951 \\
\hline 2001 & 150 & 112 & 38 & 2823 & 1977 & 846 \\
\hline 2002 & 147 & 109 & 38 & 2662 & 1889 & 773 \\
\hline 2003 & 158 & 114 & 44 & 2471 & 1763 & 708 \\
\hline 2004 & 148 & 111 & 37 & 2423 & 1739 & 684 \\
\hline 2005 & 149 & 109 & 40 & 2340 & 1633 & 707 \\
\hline 2006 & 141 & 110 & 31 & 2238 & 1623 & 615 \\
\hline 2007 & 126 & 100 & 26 & 2322 & 1674 & 648 \\
\hline 2008 & 120 & 87 & 33 & 2337 & 1620 & 717 \\
\hline 2009 & 122 & 93 & 29 & 2327 & 1676 & 651 \\
\hline 2010 & 115 & 91 & 24 & 2057 & 1454 & 603 \\
\hline 2011 & 112 & 90 & 22 & 1836 & 1258 & 578 \\
\hline 2012 & 107 & 82 & 25 & 1791 & 1276 & 515 \\
\hline 2013 & 92 & 71 & 21 & 1684 & 1164 & 520 \\
\hline 2014 & 99 & 71 & 28 & 1583 & 1084 & 499 \\
\hline 2015 & 80 & 60 & 20 & 1476 & 1067 & 409 \\
\hline 2016 & 91 & 67 & 24 & 1522 & 1094 & 428 \\
\hline 2017 & 72 & 53 & 19 & 1604 & 1136 & 468 \\
\hline
\end{tabular}

Source: Developed by the author based on Central Statistical Office (GUS) data www.stat.gov.pl [1]

rate. A slightly different characteristic related to the mortality of girls. In this case, the province rate more often assumed higher values than nationwide (Table 4).

However, a detailed analysis of the distribution of infant mortality by place of residence in the years 2000 2017 showed that throughout the whole period considered, the absolute number of deaths of infants living in Podkarpackie province in the rural area was higher than in the city. However, due to differences in the structure of the place of residence, over the years, the relationship between the mortality rates per 1000 live births in both groups changes periodically. The infant mortality rate in rural areas prevailed in 2001-2003, 2007, 2009-2014, and 2016-2017. In the case of Poland, a slightly different situation was observed, since in almost all years of the initial 10 of the analysed period, infant mortality in the urban area was higher than in the rural areas. It was reversed in 2010. The number of infant deaths both in the urban area and in the rural areas decreased in Podkarpackie province by almost $60 \%$, while in the country by almost $50 \%$ (Tables 5 and 6).

The infant mortality rate in rural areas in Podkarpackie province in the entire analysed period remained at a level similar to the national rate. In cities, however, its significant advantage was observed in Podkarpackie province in the years 2004-2006 (Table 6).



Source: Developed by the author based on (entral Statistical Office (GUS) data www.stat.gov.pl [1] FIGURE 1. Infant mortality in Poland against the background of live births

The mean annual rate of decline in infant mortality in Podkarpackie province (4.5\%) was higher in the analysed period than in the country (4.1\%). An analogous relation was also found in all separate categories except for "boys".

\section{INFANT MORTALITY FORECAST FOR 2018-2025}

Based on known values of the infant mortality rate in the years 2000-2017, the forecast for 2018-2025 was established in Podkarpackie province. For this purpose, 
TABLE 2. Infant mortality rate in the years 2000-2017

\begin{tabular}{|c|c|c|c|c|c|c|}
\hline \multirow[t]{3}{*}{ Years } & \multicolumn{6}{|c|}{ Infant mortality rate per 1000 live births } \\
\hline & \multicolumn{3}{|c|}{ Podkarpackie province } & \multicolumn{3}{|c|}{ Poland } \\
\hline & Total & Neonates & Other infants & Total & Neonates & Other infants \\
\hline 2000 & 7.17 & 5.13 & 2.04 & 8.11 & 5.59 & 2.52 \\
\hline 2001 & 6.78 & 5.06 & 1.72 & 7.67 & 5.36 & 2.31 \\
\hline 2002 & 6.90 & 5.12 & 1.78 & 7.52 & 5.33 & 2.19 \\
\hline 2003 & 7.70 & 5.56 & 2.14 & 7.04 & 5.01 & 2.02 \\
\hline 2004 & 7.21 & 5.41 & 1.80 & 6.80 & 4.88 & 1.93 \\
\hline 2005 & 7.26 & 5.31 & 1.95 & 6.42 & 4.48 & 1.94 \\
\hline 2006 & 6.95 & 5.42 & 1.53 & 5.98 & 4.34 & 1.64 \\
\hline 2007 & 6.01 & 4.77 & 1.24 & 5.99 & 4.32 & 1.67 \\
\hline 2008 & 5.40 & 3.92 & 1.49 & 5.64 & 3.92 & 1.72 \\
\hline 2009 & 5.45 & 4.15 & 1.30 & 5.57 & 4.01 & 1.56 \\
\hline 2010 & 5.23 & 4.14 & 1.09 & 4.98 & 3.52 & 1.46 \\
\hline 2011 & 5.30 & 4.26 & 1.04 & 4.73 & 3.24 & 1.49 \\
\hline 2012 & 5.08 & 3.89 & 1.19 & 4.64 & 3.31 & 1.33 \\
\hline 2013 & 4.52 & 3.49 & 1.03 & 4.56 & 3.15 & 1.41 \\
\hline 2014 & 4.96 & 3.56 & 1.40 & 4.22 & 2.89 & 1.33 \\
\hline 2015 & 4.09 & 3.07 & 1.02 & 4.00 & 2.89 & 1.11 \\
\hline 2016 & 4.49 & 3.31 & 1.18 & 3.98 & 2.86 & 1.12 \\
\hline 2017 & 3.28 & 2.42 & 0.87 & 3.99 & 2.83 & 1.16 \\
\hline
\end{tabular}

Source: Developed by the author based on Central Statistical Office (GUS) data www.stat.gov.pl [1]

TABLE 3. Distribution of infant mortality in terms of sex in the years 2000-2017

\begin{tabular}{|l|c|c|c|c|c|c|}
\hline \multirow{2}{*}{ Years } & \multicolumn{5}{|c|}{ Number of deaths } \\
\cline { 2 - 7 } & \multicolumn{5}{|c|}{ Podkarpackie province } & \multicolumn{2}{c|}{ Toland } \\
\cline { 2 - 7 } & Total & Boys & Girls & 3067 & 1718 & 1349 \\
\hline 2000 & 169 & 86 & 83 & 2823 & 1577 & 1246 \\
\hline 2002 & 150 & 90 & 60 & 2662 & 1490 & 1172 \\
\hline 2003 & 147 & 81 & 66 & 2471 & 1384 & 1087 \\
\hline 2004 & 158 & 83 & 75 & 2423 & 1363 & 1060 \\
\hline 2005 & 148 & 89 & 59 & 2340 & 1304 & 1036 \\
\hline 2006 & 149 & 78 & 71 & 2238 & 1278 & 960 \\
\hline 2007 & 141 & 90 & 51 & 2322 & 1302 & 1020 \\
\hline 2008 & 126 & 66 & 60 & 2337 & 1302 & 1035 \\
\hline 2009 & 120 & 64 & 56 & 2327 & 1298 & 1029 \\
\hline 2010 & 122 & 63 & 59 & 2057 & 1155 & 902 \\
\hline 2011 & 115 & 63 & 52 & 1836 & 1027 & 809 \\
\hline 2012 & 112 & 58 & 54 & 1791 & 995 & 796 \\
\hline 2013 & 107 & 61 & 46 & 1684 & 937 & 747 \\
\hline 2014 & 92 & 49 & 43 & 1583 & 870 & 713 \\
\hline 2015 & 99 & 57 & 42 & 1476 & 830 & 646 \\
\hline 2016 & 80 & 46 & 34 & 1,604 & 908 & 654 \\
\hline 2017 & 72 & 43 & 29 & & & 696 \\
\hline
\end{tabular}

Source: Developed by the author based on Central Statistical Office (GUS) data www.stat.gov.pl [1] 
TABLE 4. Mortality rate in terms of sex in the years $2000-2017$

\begin{tabular}{|c|c|c|c|c|c|c|}
\hline \multirow[t]{3}{*}{ Years } & \multicolumn{6}{|c|}{ Infant mortality rate per 1000 live births } \\
\hline & \multicolumn{3}{|c|}{ Podkarpackie province } & \multicolumn{3}{|c|}{ Poland } \\
\hline & Total & Boys & Girls & Total & Boys & Girls \\
\hline 2000 & 7.17 & 7.10 & 7.23 & 8.11 & 8.83 & 7.34 \\
\hline 2001 & 6.78 & 8.06 & 5.44 & 7.67 & 8.33 & 6.96 \\
\hline 2002 & 6.90 & 7.36 & 6.41 & 7.52 & 8.18 & 6.83 \\
\hline 2003 & 7.70 & 7.83 & 7.56 & 7.04 & 7.66 & 6.38 \\
\hline 2004 & 7.21 & 8.49 & 5.87 & 6.80 & 7.43 & 6.14 \\
\hline 2005 & 7.26 & 7.32 & 7.19 & 6.42 & 6.96 & 5.85 \\
\hline 2006 & 6.95 & 8.62 & 5.18 & 5.98 & 6.64 & 5.28 \\
\hline 2007 & 6.01 & 6.13 & 5.89 & 5.99 & 6.55 & 5.39 \\
\hline 2008 & 5.40 & 5.69 & 5.09 & 5.64 & 6.13 & 5.13 \\
\hline 2009 & 5.45 & 5.47 & 5.44 & 5.57 & 6.04 & 5.08 \\
\hline 2010 & 5.23 & 5.57 & 4.87 & 4.98 & 5.39 & 4.54 \\
\hline 2011 & 5.30 & 5.36 & 5.24 & 4.73 & 5.14 & 4.29 \\
\hline 2012 & 5.08 & 5.60 & 4.52 & 4.64 & 5.01 & 4.24 \\
\hline 2013 & 4.52 & 4.71 & 4.32 & 4.56 & 4.93 & 4.16 \\
\hline 2014 & 4.96 & 5.58 & 4.31 & 4.22 & 4.51 & 4.07 \\
\hline 2015 & 4.09 & 4.61 & 3.54 & 4.00 & 4.38 & 3.60 \\
\hline 2016 & 4.49 & 5.00 & 3.96 & 3.98 & 4.42 & 3.52 \\
\hline 2017 & 3.28 & 3.80 & 2.73 & 3.99 & 4.40 & 3.56 \\
\hline
\end{tabular}

Source: Developed by the author based on Central Statistical Office (GUS) data www.stat.gov.pl [1]

TABLE 5. Distribution of infant mortality in terms of sex in years 2000-2017

\begin{tabular}{|c|c|c|c|c|c|c|}
\hline \multirow[t]{3}{*}{ Years } & \multicolumn{6}{|c|}{ Number of deaths } \\
\hline & \multicolumn{3}{|c|}{ Podkarpackie province } & \multicolumn{3}{|c|}{ Poland } \\
\hline & Total & Urban area & Rural area & Total & Urban area & Rural area \\
\hline 2000 & 169 & 62 & 107 & 3067 & 1724 & 1343 \\
\hline 2001 & 150 & 51 & 99 & 2823 & 1575 & 1248 \\
\hline 2002 & 147 & 48 & 99 & 2662 & 1548 & 1114 \\
\hline 2003 & 158 & 56 & 102 & 2471 & 1448 & 1023 \\
\hline 2004 & 148 & 69 & 79 & 2423 & 1462 & 961 \\
\hline 2005 & 149 & 60 & 89 & 2340 & 1339 & 1001 \\
\hline 2006 & 141 & 66 & 75 & 2238 & 1343 & 895 \\
\hline 2007 & 126 & 44 & 82 & 2322 & 1371 & 951 \\
\hline 2008 & 120 & 51 & 69 & 2337 & 1363 & 974 \\
\hline 2009 & 122 & 40 & 82 & 2327 & 1385 & 942 \\
\hline 2010 & 115 & 42 & 73 & 2057 & 1198 & 859 \\
\hline 2011 & 112 & 33 & 79 & 1836 & 1059 & 777 \\
\hline 2012 & 107 & 41 & 66 & 1791 & 1006 & 785 \\
\hline 2013 & 92 & 32 & 60 & 1684 & 928 & 756 \\
\hline 2014 & 99 & 37 & 62 & 1583 & 885 & 698 \\
\hline 2015 & 80 & 32 & 48 & 1476 & 859 & 617 \\
\hline 2016 & 91 & 32 & 59 & 1522 & 876 & 646 \\
\hline 2017 & 72 & 28 & 44 & 1604 & 931 & 673 \\
\hline
\end{tabular}

Source: Developed by the author based on Central Statistical Office (GUS) data www.stat.gov.pl [1] 
TABLE 6. Mortality rate in terms of place of residence in the years 2000-2017

\begin{tabular}{|c|c|c|c|c|c|c|}
\hline \multirow[t]{3}{*}{ Years } & \multicolumn{6}{|c|}{ Infant mortality rate per 1000 live births } \\
\hline & \multicolumn{3}{|c|}{ Podkarpackie province } & \multicolumn{3}{|c|}{ Poland } \\
\hline & Total & Urban area & Rural area & Total & Urban area & Rural area \\
\hline 2000 & 7.17 & 7.65 & 6.91 & 8.11 & 8.28 & 7.90 \\
\hline 2001 & 6.78 & 6.71 & 6.81 & 7.67 & 7.66 & 7.68 \\
\hline 2002 & 6.90 & 6.47 & 7.12 & 7.52 & 7.86 & 7.11 \\
\hline 2003 & 7.70 & 7.64 & 7.73 & 7.04 & 7.25 & 6.76 \\
\hline 2004 & 7.21 & 9.31 & 6.02 & 6.80 & 7.14 & 6.35 \\
\hline 2005 & 7.26 & 7.89 & 6.89 & 6.42 & 6.34 & 6.53 \\
\hline 2006 & 6.95 & 8.73 & 5.90 & 5.98 & 6.16 & 5.73 \\
\hline 2007 & 6.01 & 5.56 & 6.28 & 5.99 & 6.08 & 5.86 \\
\hline 2008 & 5.40 & 5.99 & 5.03 & 5.64 & 5.65 & 5.63 \\
\hline 2009 & 5.45 & 4.54 & 6.05 & 5.57 & 5.62 & 5.50 \\
\hline 2010 & 5.23 & 4.90 & 5.44 & 4.98 & 4.95 & 5.01 \\
\hline 2011 & 5.30 & 4.01 & 6.12 & 4.73 & 4.69 & 4.78 \\
\hline 2012 & 5.08 & 5.01 & 5.13 & 4.64 & 4.50 & 4.83 \\
\hline 2013 & 4.52 & 4.03 & 4.83 & 4.56 & 4.34 & 4.85 \\
\hline 2014 & 4.96 & 4.74 & 5.10 & 4.22 & 4.07 & 4.43 \\
\hline 2015 & 4.09 & 4.12 & 4.07 & 4.00 & 3.95 & 4.06 \\
\hline 2016 & 4.49 & 3.97 & 4.83 & 3.98 & 3.87 & 4.14 \\
\hline 2017 & 3.28 & 3.28 & 3.29 & 3.99 & 3.94 & 4.06 \\
\hline
\end{tabular}

Source: Developed by the author based on Central Statistical Office (GUS) data www.stat.gov.pl [1]

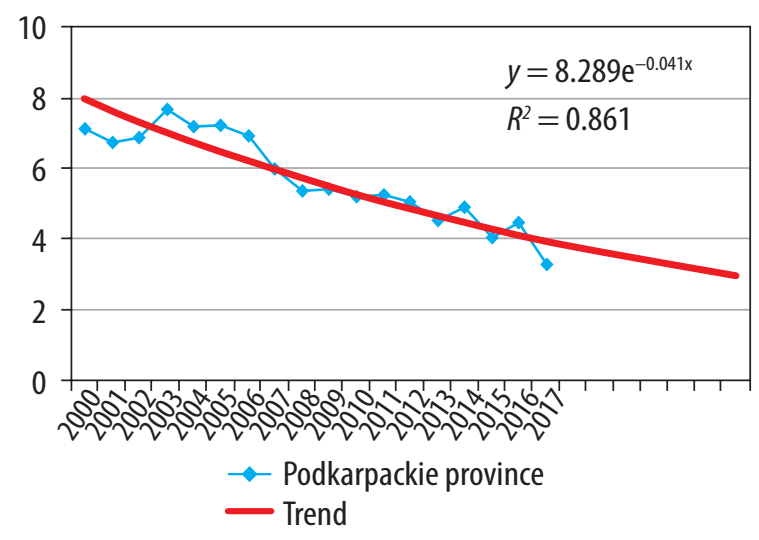

Source: Developed by the author based on Central Statistical Office (GUS) data www.stat.gov.pl [1] FIGURE 2. Infant mortality in Podkarpackie province and the mortality trend

the regression function in the exponential form was used, because in the analysed case it was characterised by the best fit to the empirical data. The obtained trend function together with its mathematical equation is presented below (Fig. 2).

The high value of the determination coefficient $(0.861)$ indicates a good fit of the obtained model because more than $86 \%$ of the overall variability of the infant mortality rate is explained by it. The forecasted values of the infant mortality rate based on this model in the years 2015-2025
TABLE 7. The mean annual rate of decline in the infant mortality rate in 2000-2017

\begin{tabular}{|l|c|c|}
\hline Characteristic & Podkarpackie province (\%) & Poland (\%) \\
\hline Total & 4.5 & 4.1 \\
\hline Neonates & 4.3 & 3.9 \\
\hline Other infants & 4.9 & 4.5 \\
\hline Urban area & 4.9 & 4.3 \\
\hline Rural area & 4.3 & 3.8 \\
\hline Boys & 3.6 & 4.0 \\
\hline Girls & 5.6 & 4.2 \\
\hline
\end{tabular}

Source: Developed by the author based on Central Statistical Office (GUS) data www.stat.gov.pl [1]

in Podkarpackie province are included in the table below (Table 8).

\section{DISCUSSION}

In the years 2000-2017, infant mortality in Poland continued to decline. According to data from the Central Statistical Office, in 2017, 1604 deaths of children in the first year of life were registered, while in 2000 this figure was 3067 . The infant mortality rate in Poland was 
3.99 per 1000 live births, which was 4.12 lower than the rate from 2000 (8.11). Despite the change in the infant mortality rate being so favourable for the size of the population of children in Poland, its level is still higher than in 20 other countries in the European Union. In 2016, about 18,600 children died in the European Union in the first year of life, which corresponds to the infant mortality rate of 3.6 deaths per 1000 live births. Lower rates than in Poland were noted, among others, in Finland (1.9), Slovenia (2.0), Estonia (2.3), and Sweden (2.5) and higher in countries such as Malta (7.4), Romania (7.0), Bulgaria (6.5), Lithuania (4.5), or Slovakia (5.4). When comparing national data with Europe, we should mark a decisive shortening of the distance that divided us from the countries of the "old European Union" not so long ago. This is a good prognosis for the coming years.

A positive downward trend in the number of infant deaths was observed in Podkarpackie province in the years 2000-2017, as well as in the whole of Poland. It is worth emphasising that the average rate of decline in infant mortality in Podkarpackie province (4.5\%) was higher in the analysed period than in the whole country (4.1\%). The infant mortality rate in Podkarpackie province decreased in this period from 7.17 to 3.28 per 1000 live births, i.e. by $54 \%$ (in Poland by $51 \%$ ). Slight fluctuations in both these ratios meant that they exchanged the dominating role over the analysed years, but only in the years 2000-2002, 2008-2009, and 2017 did the national index exceed the provincial value. The largest number of infants died in the neonatal period, accounting for about $70 \%$ of all deaths of children in the first year of life, both in Poland and in Podkarpackie province but only in the years 2000-2002, 2008-2009, and 2017 did the national index exceeded the provincial value.

Throughout the considered period in Podkarpackie province, deaths of male infants prevailed. Also, in Poland, boys died with greater intensity, and while in the case of the whole of Poland the difference between the number of deaths of boys and girls remained at similar levels throughout the year (20-25\%), in Podkarpackie province there were significant fluctuations in individual years (4-43\%). Thus, the relative percentage difference in the mortality rate of male and female babies still persists both in Poland and in Podkarpacie province.

The greater risk of boys dying during pregnancy and infancy is widely known. Both foetal and neonatal death rates show higher values in the case of male sex. Similarly, boys prevail among preterm infants [5-8]. Statistical data obtained from the National Centre for Medical Statistics of the USA show that the mortality rate of female infants was about $18 \%$ lower than the analogical indicator for boys [8]. The observed lower rate of lung maturation in male foetuses, increased number of premature births, and related complications during infancy (motor, neurological, and other disorders and deficits) may indirectly explain the higher mortality of boys in infancy and later
TABLE 8. Forecast value of infant mortality in the Podkarpackie province in the years 2018-2025

\begin{tabular}{|l|c|}
\hline Years & Infant mortality \\
\hline 2018 & 3.80 \\
\hline 2019 & 3.65 \\
\hline 2020 & 3.50 \\
\hline 2021 & 3.36 \\
\hline 2022 & 3.23 \\
\hline 2023 & 3.10 \\
\hline 2024 & 2.97 \\
\hline 2025 & 2.85 \\
\hline
\end{tabular}

Source: Developed by the author based on Central Statistical Office (GUS) data www.stat.gov.pl [1]

$[6,9]$. One theory explains differences in mortality from a biological perspective. It assumes that the causes of "excess mortality of boys" compared to girls are largely dependent on genetic differences.

As is known, the male sex determines the pair of XY chromosomes, while the female gender is the XX pair. In girls, possible aberrations of one $\mathrm{X}$ chromosome are eliminated by the functions of the other, in the case of boys - anomalies of the X chromosome cannot be "replaced" by the Y chromosome [10]. Similar importance is also attributed to hormonal, metabolic, and even evolutionary factors, but they have not been documented in a reliable manner [9, 11].

Analysis of infant mortality with respect to the mother's place of residence showed that the absolute number of deaths of infants living in Podkarpackie province in rural areas was higher than in the urban area; however, relations between indicators changed in terms of 1000 live births in a given group in 2000-2017. The mortality rate of rural children prevailed between 2001-2003, 2007, 2009-2014, and 2016-2017. Its course differed from the national index, which for a long time had values lower than for the city. It was only from 2010 to 2017 that the difference in the mortality rate was in favour of urban areas. Regardless of the varied pace of reduction of mortality rates of urban and rural infants, it should be stated that in Podkarpackie province, the level of mortality between urban and rural areas is slowly becoming equal. The same situation happening in Poland, and although in 2002-2011 the national infant mortality rate was 4\% higher in the city, only in three provinces (Opolskie, Pomorskie, and Śląskie) was the difference significantly high. In the remaining provinces - including Podkarpackie province - no statistically significant differences were found between urban and rural areas [12].

The reasons for the above-mentioned trend are manifold. First of all, blurring of the differences between the city and the village is observed, both in terms of social and living conditions, and preferred lifestyles. Secondly, the inhabitants of a village take advantage of the city's ci- 
vilisational benefits, but spend their daily lives in a better environment in terms of ecology. Pregnant women in rural areas are less exposed to negative ecological factors (dust, air pollution, noise, toxic contamination) than urban women, which adversely affects the developing foetus. In addition, access to health services has improved significantly in rural areas, and most municipal health care facilities already use modern medical equipment [2, 12]. In addition, health awareness and care for one's own health have increased significantly in rural areas; hence, the levelling of infant mortality between the city and the countryside is not a surprise.

Subsequently, the infant mortality forecast was made for the Podkarpackie province in 2018-2025. It is estimated that the mortality rate will decrease from 3.57 per 1000 live births to 2.85 , which is an optimistic result.

\section{CONCLUSIONS}

In the years 2000-2017, the infant mortality rate in Podkarpackie province continued to decrease, and the mean decline in the mortality rate exceeded the national rate (Podkarpackie 4.5\%, Poland 4.1\%).

A phenomenon of excess mortality of boys among babies was observed in the entire analysed period, both in the Podkarpackie region (though with large fluctuations) as well as in Poland.

The infant mortality rate in rural areas in the Podkarpackie province remained at a level similar to the national one in the entire analysed period. On the other hand, a significant advantage of the cities was observed periodically in Podkarpackie province.

\section{DISCLOSURE}

The authors declare no conflict of interest.

\section{REFERENCES}

1. The Central Statistical Office. www.stat.gov.pl.

2. UNICEF, WHO, World Bank i UN-DESA Population Division. Levels and Trends in Child Mortality Report 2018, Estimates Developed by the UN Inter-Agency Group for Child Mortality Estimation.

3. https://www.who.int/life-course/partners/global-strategy/globalstrategyreport2016-2030-lowres.pdf

4. Jołkiewicz D. Umieralność niemowląt wskaźnikiem warunków życia oraz rozwoju społecznego i cywilizacyjnego. Fam Med Primary Care Rev 2007; 9: 97-106.

5. Zeitlin J, Saurel-Cubizolles M-J, de Mouzon J, et al. Fetal sex and preterm birth: are males at greater risk? Hum Reprod 2002; 17: 2762-2768.

6. Khoury MJ, Marks JS, McCarthy BJ, Zaro SM. Factors affecting the sex differential in neonatal mortality: The role of respiratory distress syndrome. Am J Obstet Gynecol 1985; 151: 777-782.

7. Hall MH, Carr-Hill R. Impact of sex ratio on onset and management of labour. Br Med J 1982; 285: 401-403.

8. National Center for Health Statistics 2016. www.cdc.gov/nchs/
9. Verloove-Vanhorick SP, Veen S, Ruys JH, et al. Sex difference in disability and handicap at five years of age in children born at very short gestation. Pediatrics 1994; 93: 576-579.

10. Królikowska $\mathrm{S}$. Nierówności w stanie zdrowia między kobietami a mężczyznami w kontekście płci biologicznej oraz społeczno-kulturowej," Folia Soc 2011; 39: 33-52.

11. Rosen TS, Bateman D. The role of gender in neonatology. In: Principles of Gender-Specific Medicine, Legato MJ (ed.). Elsevier Academic Press, San Diego 2004; 3-11.

12. Krzyżak M, Maślach D, Piotrowska $K$, et al. Umieralność ogólna niemowląt w mieście i na wsi w Polsce w latach 2002-2011. Probl Hig Epidemiol 2014; 95: 279-284. 